\title{
Cerebral blood flow and metabolism during open-heart surgery
}

\author{
M. A. B R A N T H W A I T E
}

Brompton Hospital, London SW3

\begin{abstract}
Branthwaite, M. A. (1974). Thorax, 29, 633-638. Cerebral blood flow and metabolism during open-heart surgery. Changes in cerebral blood flow and metabolism were investigated in 30 patients during the first five minutes of cardiopulmonary bypass. The ratio of blood flow to oxygen uptake (the cerebral blood flow equivalent or CBFE) rose by $54 \%$ and this change could not be attributed to simultaneous variations in arterial carbon dioxide tension, haematocrit or temperature.

A modified thermovelocity technique was used to assess changes in blood flow in the internal jugular vein in 12 of the 30 subjects. The method suffers from a number of serious limitations, but the evidence suggests that there was a reduction in cerebral blood flow at the onset of bypass in more than $50 \%$ of the patients studied. The fall was associated with a particularly marked reduction in systemic blood pressure and occurred in spite of high overall flow rates from the oxygenator.

It is argued that the findings indicate considerable depression of cerebral metabolism, which may be due to the decreased oxygen availability consequent upon haemodilution and hypotension and which may contribute to neurological damage in some patients.
\end{abstract}

Previous work on the aetiology of neurological damage related to open-heart surgery (Branthwaite, 1973a) identified the onset of cardiopulmonary bypass as a period of hazard and suggested that systemic hypotension resulting in inadequate cerebral blood flow may be a contributory factor. Monitoring jugular venous oxygen saturation has been advocated as a means of detecting cerebral ischaemia during cerebrovascular surgery (Lyons, Clark, McDowell, and McArthur, 1964), and although the method has limitations (Larson, Ehrenfeld, Wade, and Wylie, 1967) a study was undertaken to examine changes in jugular venous oxygenation at the onset of cardiopulmonary bypass. Changes in both blood flow and metabolic rate influence venous oxygen saturation, and, in some of the patients studied, an attempt was made therefore to combine the measurement of changes in jugular venous oxygenation with an assessment of changes in cerebral blood flow.

\section{MATERIAL AND METHODS}

Studies were made on 30 unselected adult patients (average age 45 years) undergoing surgery for a variety of congenital or acquired defects. Informed consent was obtained at the preoperative visit.

Following premedication with papaveretum and scopolamine, anaesthesia was induced with thiopentone $(3-4 \mathrm{mg} / \mathrm{kg}$ ) and pancuronium bromide and maintained with nitrous oxide $(60-67 \%)$ and oxygen (40-33\%) with additional supplements of papaveretum if necessary. Perfusion was established with a rotating disc oxygenator, and some degree of haemodilution was employed in all cases. A flow of at least $80 \mathrm{ml} / \mathrm{kg}$ was reached in less than five minutes in all cases, and in all but three, artificial ventilation had been discontinued and the aorta cross-clamped within this period.

The radial artery and internal jugular vein are cannulated routinely and, for this study, a second jugular catheter was introduced percutaneously and threaded in a retrograde direction to the base of the skull. In 12 patients, this jugular catheter consisted of a specially constructed thermovelocity probe.

Arterial and jugular venous blood samples were collected immediately before and at one-minute intervals for the first five minutes after the onset of perfusion, and were analysed for oxygen content using either a Lex-O-O-Con (Albury Instruments Ltd.) or the electrode method of Linden, Ledsome, and Norman (1965). The haematocrit (PCV) was measured on each arterial sample using a Hawkesley micro- 
haematocrit centrifuge. The arterial blood gas tensions were measured both before and five minutes after the onset of perfusion and these results were corrected for temperature when necessary. Changes in arterial and jugular venous oxygen content were expressed as the cerebral blood flow equivalent (CBFE), which represents blood flow per unit oxygen consumption and is derived as the reciprocal of the arteriovenous oxygen content difference (A-V)O, (Cotev, Lee, and Severinghaus, 1968).

In all cases the arterial and superior vena caval pressures, nasopharyngeal temperature, and the cerebral function monitor signal (a modified EEG) were recorded on an ultraviolet recorder (S.E. Laboratories Ltd.). In 12 patients changes in jugular blood flow were assessed using a modification of the thermovelocity technique (Meyer, Gotoh, Tomita, and Akiyama, 1966). Two thermistors (Standard Telephones and Cables, type U23US) were mounted in the tip of a Portex $30 \mathrm{~cm}$ nylon cannula (ID $1.2 \mathrm{~mm})$. The distal thermistor was heated three times each minute by a battery-operated constant current source while the change in temperature sensed by the proximal thermistor was amplified and recorded using the temperature-sensing circuit of a Devices thermal dilution cardiac output monitor. The integral of the temperature change detected by the sensing thermistor is inversely proportional to the velocity of blood flow past the tip of the cannula and was recorded on the same tracing as the variables enumerated above.

\section{RESULTS}

The changes which occurred during the first five minutes of perfusion are shown in Table I. The
CBFE increased from 15.2 to $23.4 \mathrm{ml} \mathrm{blood} / \mathrm{ml} \mathrm{O}_{2}$ 음 uptake and, at the same time, the mean arterial blood pressure,..superior vena caval pressure, and $\frac{5}{5}$ PCV decreased. There was a small but significant $\stackrel{\AA}{\propto}$ increase in the arterial carbon dioxide tension $\left(\mathrm{PaCO}_{2}\right)$ together with a small, but highly significant fall in nasopharyngeal temperature.

Four patients were found postoperatively to $\overrightarrow{\vec{\omega}}$ have sustained neurological damage which was a hemiplegia of varying severity in three and $a \vec{x}$ mid-brain lesion in one. The changes recorded in these four patients were compared with those in 24 undamaged patients who survived the opera- tion (Table II); two patients died on the tablew and were excluded from this comparison. Al-으 though none of the differences reached statistical significance, there was a tendency for the increase $z$ in CBFE during the first five minutes to be greater in patients who suffered neurological injury. The 3 cerebral function monitor record was unsatis- $\mathbb{\Phi}$ factory in one of these patients for technical reasons, but in the other three, there was a sudden $\theta$ change at the onset of bypass which could not. be attributed to any other variable known to influence this signal (Branthwaite, 1973b), and the remainder of these three records was unremarkable.

In the 12 patients in whom changes in cerebral $\stackrel{\mathbb{2}}{2}$ blood flow were assessed, the thermovelocity $\overrightarrow{0}$ integral height was measured for the first 153 cycles ( 5 minutes) following the onset of bypass? and compared with the last six cycles $(2$ minutes $)$.

T A B L E I

MEAN AND STANDARD ERROR OF MEAN FOR VALUES RECORDED BEFORE AND 5 MINUTES AFTER ONSET OF CARDIOPULMONARY BYPASS

\begin{tabular}{|c|c|c|c|c|}
\hline & Before & $5 \mathrm{~min}$. & Mean Diff. & Significance \\
\hline 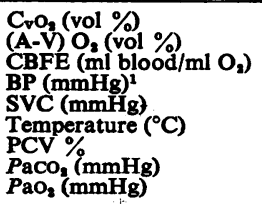 & $\begin{array}{r}8.9 \pm 0.6 \\
7 \cdot 3 \pm 0.4 \\
15 \cdot 2 \pm 1.0 \\
79.0 \pm 2.1 \\
11.4 \pm 0.9 \\
36 \cdot 3 \pm 0.1 \\
41 \cdot 3 \pm 0.9 \\
33.0 \pm 1.1 \\
104.4 \pm 4.4\end{array}$ & $\begin{array}{r}5 \cdot 2 \pm 0.5 \\
5 \cdot 1 \pm 0 \cdot 4 \\
23 \cdot 4 \pm 2 \cdot 2 \\
44 \cdot 0 \pm 2 \cdot 3 \\
1.9 \pm 0.7 \\
35 \cdot 8 \pm 0 \cdot 2 \\
28 \cdot 1 \pm 0.9 \\
35 \cdot 2 \pm 1 \cdot 1 \\
100 \cdot 0 \pm 6.9\end{array}$ & $\begin{array}{r}-3.66 \pm 0.56 \\
-2.27 \pm 0.54 \\
8.3 \pm 2.0 \\
-35.7 \pm 3.17 \\
-9.5 \pm 0.9 \\
-0.5 \pm 0.15 \\
-13.1 \pm 0.6 \\
2.2 \pm 0.8 \\
-4.4 \pm 6.92\end{array}$ & $\begin{array}{l}<0.001 \\
<0.001 \\
<0.001 \\
<0.001 \\
<0.001 \\
<0.01 \\
<0.001 \\
<0.05 \\
>0.1\end{array}$ \\
\hline
\end{tabular}

1Pulsatile pressures were adjusted to a calculated mean by taking diastolic pressure $+(1 / 3 \times$ pulse pressure $)$.

T A B L E I I

COMPARISON OF CHANGES OCCURRING DURING FIRST 5 MINUTES OF CARDIOPULMONARY BYPASS IN FOUR PATIENTS WITH NEUROLOGICAL DAMAGE AND 24 UNDAMAGED SURVIVORS

\begin{tabular}{|c|c|c|c|c|}
\hline$x^{\infty} \quad r$ & $\begin{array}{l}4 \text { Patients with } \\
\text { CNS Damage }\end{array}$ & $\begin{array}{l}24 \text { Undamaged } \\
\text { Survivors }\end{array}$ & $\begin{array}{l}\text { Mean Diff. } \\
\quad \pm \text { SEM }\end{array}$ & Significance \\
\hline 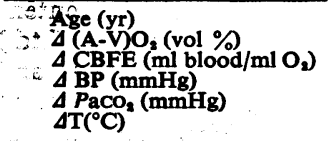 & $\begin{array}{c}53 \cdot 8 \\
-3 \cdot 83 \\
18 \cdot 2 \\
-32 \cdot 5 \\
2 \cdot 4 \\
-0.25\end{array}$ & $\begin{array}{c}42 \cdot 3 \\
-2 \cdot 18 \\
7 \cdot 3 \\
-36 \cdot 2 \\
1 \cdot 8 \\
-0.62\end{array}$ & $\begin{array}{c}11.5 \pm 7.4 \\
-1.65 \pm 1.63 \\
10.9 \pm 5.74 \\
3.7 \pm 9.4 \\
0.6 \pm 2.2 \\
0.37 \pm 0.42\end{array}$ & $\begin{array}{l}\text { NS } \\
\text { NS } \\
0.1 \mathrm{P}>0.05 \\
\text { NS } \\
\text { NS } \\
\text { NS }\end{array}$ \\
\hline
\end{tabular}


preceding the onset. Although the circuit was arranged to compensate for minor changes in background temperature, this could not eliminate the effects of rapid changes, and there were some minor, transitory temperature changes which resulted in obviously artefactual signals (Fig. 4) which were discounted.

For the group as a whole, there was no significant change in integral height following the onset of perfusion, but there was considerable variation between patients, in five of whom there was a significant fall, whereas in seven there was either no change or an increase. There was a greater increase in $\mathrm{PaCO}_{2}$ and a tendency towards a smaller fall in mean arterial blood pressure in the five patients in whom the integral height fell, than in the seven patients in whom the integral height either increased or remained unchanged (Table III).

\section{DISCUSSION}

A number of the physiological variables which change acutely at the onset of cardiopulmonary bypass could influence either cerebral blood flow or cerebral metabolic rate and so lead to the increase in CBFE which has been documented here.

In normal circumstances $\mathrm{PaCO}_{2}$ is the most important determinant of cerebral blood flow which rises approximately $1 \mathrm{ml} / 100 \mathrm{~g}$ per minute for each increment of $1 \mathrm{~mm}$ in $\mathrm{PaCO}_{2}$ (Smith and Wollman, 1972). The behaviour of the cerebral vessels when subjected to an alteration in $\mathrm{PaCO}_{2}$ during perfusion is a matter of dispute (Halley, Reemtsma, and Creech, 1958; Wollman, Stephen, Clement, and Danielson, 1966), but even if the response is normal, the predicted increase in CBFE due to the increase in $\mathrm{PaCO}_{2}$ in the present study would only be of the order of $6 \%$.

The effect of dilutional anaemia on cerebral blood flow and metabolism was studied in dogs by Michenfelder and Theye (1969), who found that a fall in haemoglobin concentration from 12.4 to $7 \cdot 8 \mathrm{~g} / 100 \mathrm{ml}$ (a decrease of $37 \cdot 1 \%$ ) resulted in an increase in CBFE from 16.1 to $19.4 \mathrm{ml}$ blood $/ \mathrm{ml} \mathrm{O}_{2}$ uptake. This was achieved by an increase in cerebral blood flow, while the cerebral metabolic rate remained unchanged. In the present study a fall in haematocrit from 41.3 to $28.1 \%$ (a reduction by $32 \%$ of the initial value) was associated with an increase in CBFE from

\footnotetext{
Thermal conductivity of blood: $506 \mathrm{~mW} \mathrm{~m}^{-1} \mathrm{~K}^{-1}$

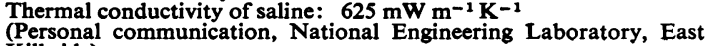
Kilbride)
}

15.2 to $23.4 \mathrm{ml} \mathrm{blood} / \mathrm{ml} \mathrm{O}_{2}$ uptake ( $+54 \%$ ), which is more than twice the change recorded by Michenfelder and Theye (1969) for a comparable degree of haemodilution in dogs. Even if the same mechanism applies in man, the increase in CBFE in the present study was out of proportion to the change in haematocrit.

Both cerebral blood flow and metabolic rate can be influenced by changes in body temperature (Michenfelder and Theye, 1968), but the reduction of only $0.5^{\circ} \mathrm{C}$ which was recorded in the present series could not be expected to change the CBFE by more than approximately $3 \%$.

The mean arterial blood pressure fell at the onset of perfusion to $44 \mathrm{mmHg}$, which is below the value at which, in normal circumstances, autoregulation can preserve a normal cerebral blood flow (Harper, 1965). It is possible, however, that the reduction in cerebral blood flow which would be expected to result from this hypotension did not occur because the overall flow rate from the oxygenator was high $(80 \mathrm{ml} / \mathrm{kg}$ per minute). This emphasized the need to make some assessment of changes in cerebral blood flow at the onset of cardiopulmonary bypass, but many of the conventional measurement techniques are inapplicable in these circumstances. It is a time when a number of variables change acutely, the lungs are excluded from the circulation, the head vessels are not exposed, and the patient is fully heparinized so that intra-arterial injection or cannulation is more hazardous than usual. The thermovelocity technique was selected in spite of its disadvantages (Ingvar and Lassen, 1965) because it enables small, rapid changes in venous flow to be detected.

The height of the integrated signal derived from the thermovelocity system is inversely proportional to the velocity of blood flow past the tip of the probe, but velocity and volume flow are only related consistently if the diameter of the vessel remains constant. A typical calibration curve of integral height plotted against volume flow in tubing of comparable diameter to the normal internal jugular vein is shown (Fig. 1). A decrease in the diameter of the vein probably results from the abrupt reduction in superior vena caval pressure which occurs at the onset of bypass (Table I). Even if the cerebral blood flow did not alter, reduction in the diameter of the vein would increase the velocity of blood flow and so decrease the height of the integrated thermovelocity signal. In addition, the slight increase in thermal conductivity caused by haemodilution ${ }^{1}$ would enhance thermal dissipation and so accentuate the pre- 


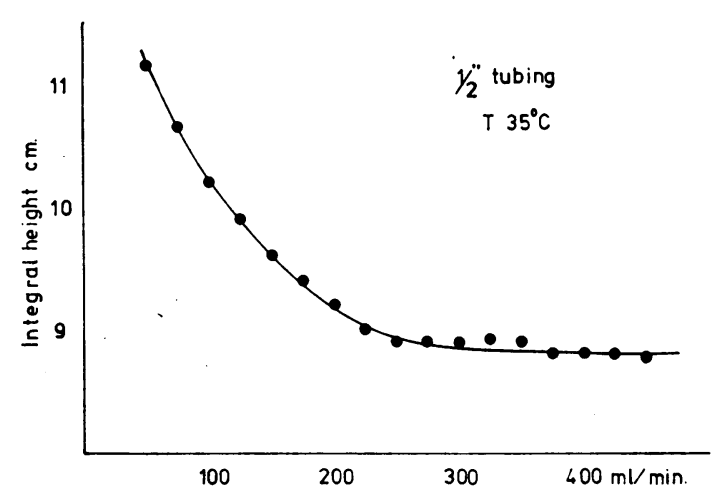

FIG. 1. Calibration curve showing change in height of integrated thermovelocity signal against volume flow rate.

dicted reduction in integral height. An increase in cerebral blood flow would accentuate this reduction in integral height still further, whereas a fall in cerebral blood flow would tend to offset it. If the fall in cerebral blood flow was profound, it would be sufficient ultimately to obliterate the combined effect of a decrease in vessel diameter and haemodilution, and the integral height would therefore remain unchanged or even increase (Figs 2-4).

In five out of 12 patients, a significant fall in integral height was recorded; in the remaining seven instances the integral height either rose or remained unchanged, which, for the reasons outlined above, implies that the cerebral blood flow had fallen in these patients. The tendency towards a greater reduction in arterial blood pressure and a smaller increase in $\mathrm{PaCO}_{2}$ in this group has been noted already (Table III).

Unequivocal conclusions cannot be drawn from this study because of the limitations of the thermovelocity method, in particular its limited resolution, the inconsistent relationship between volume and velocity of flow, and the influence of other factors such as haemodilution. However, the findings favour the hypothesis that in at least $50 \%$ of patients, cerebral blood flow falls at the onset of cardiopulmonary bypass in association with sudden systemic hypotension. This fall occurs in spite of high overall flow rates but may be offset to some extent by an increase in arterial carbon dioxide tension.

The combination of hypotension and a fall in cerebral blood flow, together with a reduction in haematocrit due to haemodilution, must seriously impair oxygen availability at tissue level (Nunn and Freeman, 1964), and it is of particular interest that the CBFE rose consistently; this must indicate a very considerable fall in cerebral metabolic rate.

The increase in CBFE at the onset of perifusion tended to be greater in patients who suffered cerebral injury, and arterialization of jugular venous blood has been recorded previously in patients suffering from cerebral damage (Shalit et al., 1970; Alexander and Lassen, 1970). It would appear that profound cerebral depression probably occurs at the onset of cardiopulmonary bypass and that the most likely mechanism is a widespread reduction in oxygen availability, although redistribution of cerebral blood flow, perhaps related to loss of the pulsatile component of the pressure waveform, may also be important (Sanderson, Wright, and Sims, 1972). High flow rates from the oxygenator confer no protection, and the extent to which the individual patient can tolerate these conditions cannot be predicted. A sudden change in cerebral electrical activity, which is generally detectable with the cerebral function monitor, is a valuable warning sign, and prompt treatment of hypotension and the avoidance of hypocapnia are useful prophylactic measures.

I am grateful to Mr. S. C. Lennox, F.R.C.S., for 옥 permission to study patients under his care. The work $D$ has been supported by a grant from the Medical Research Council, and the results will be included

T A B L E I I I

COMPARISON OF CHANGES DURING FIRST 5 MINUTES OF BYPASS

\begin{tabular}{|c|c|c|c|c|}
\hline 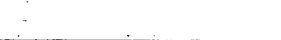 & Group $\mathbf{A}^{\mathbf{1}}$ & Group B2 & Mean Diff./SEM & Significance \\
\hline 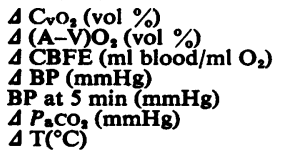 & $\begin{array}{r}-4 \cdot 22 \\
-2 \cdot 36 \\
6.34 \\
-28 \cdot 8 \\
45.0 \\
5.8 \\
-0.04\end{array}$ & $\begin{array}{r}-5 \cdot 07 \\
-1 \cdot 77 \\
8 \cdot 50 \\
-49 \cdot 0 \\
33 \cdot 3 \\
1.53 \\
-0.64\end{array}$ & $\begin{array}{r}-0.85 \pm 2.28 \\
0.59 \pm 2.33 \\
2 \cdot 16 \pm 6.96 \\
-20.2 \pm 9.79 \\
-11.7 \pm 5.7 \\
-4.27 \pm 1.76 \\
-0.60 \pm 0.44\end{array}$ & $\begin{aligned} & >0.1 \\
& >0.1 \\
& >0.1 \\
0.1 & >P>0.05 \\
0.1 & >P>0.05 \\
& <0.05 \\
& >0.1\end{aligned}$ \\
\hline
\end{tabular}

${ }^{1}$ Patients in whom height of integral thermovelocity signal fell.

'Patients in whom height of integrated thermovelocity signal increased or remained unchanged. 


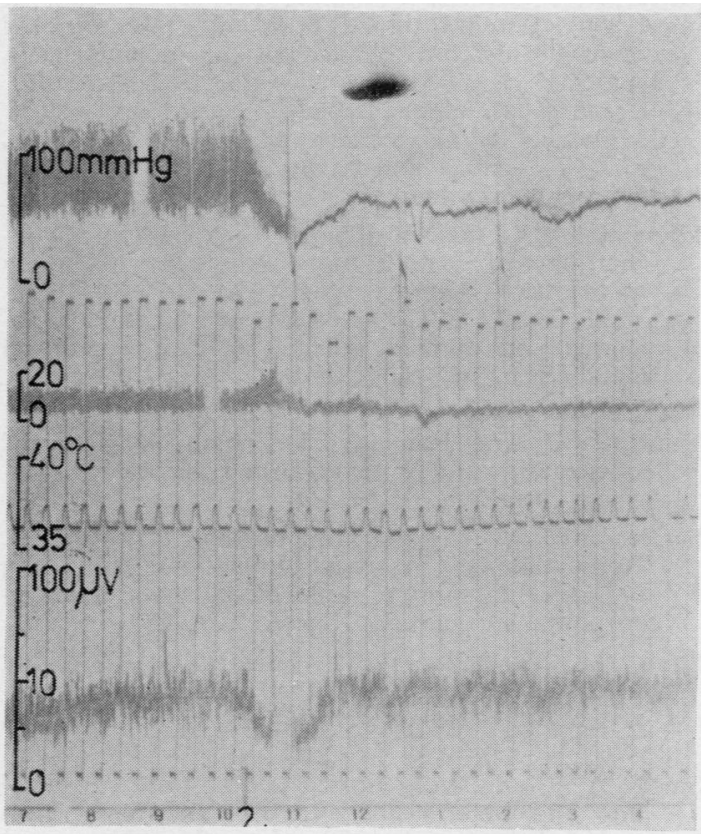

FIG. 2. Duration of record $14 \mathrm{~min}$; marker 2-on bypass.

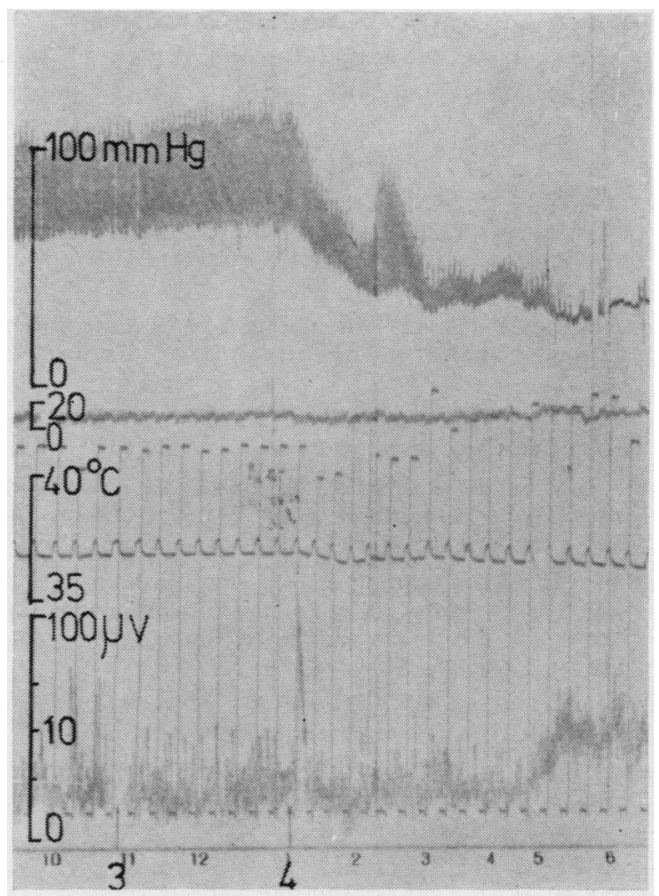

FIG. 3. Duration of record 11 min; marker 3collection of by-pass samples, marker 4-on bypass.

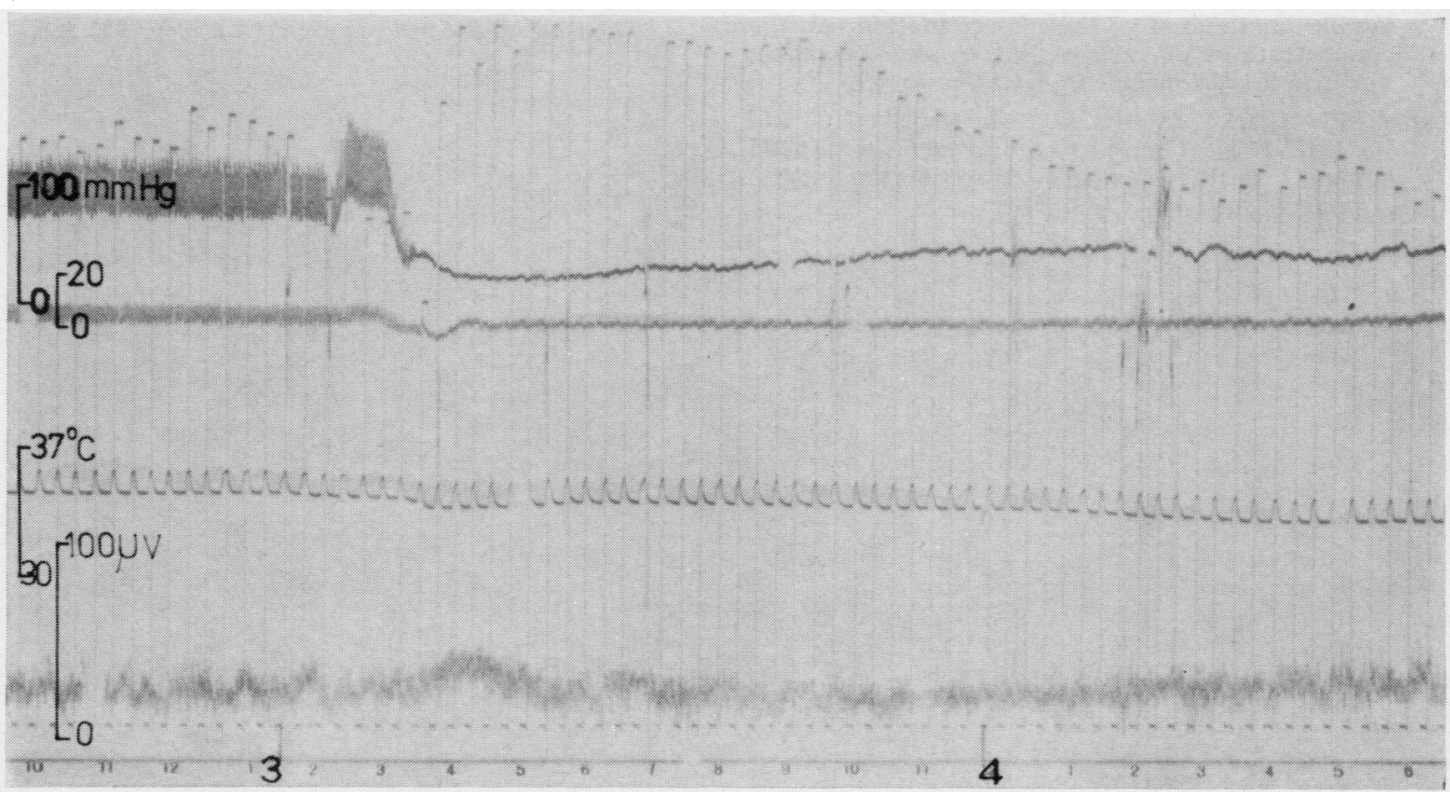

FIG. 4. Duration of record 27 min; marker 3-on bypass, marker 4 -artefact due to flushing probe with cold saline. FIGS 2-4: Onset of cardiopulmonary bypass associated with moderate, severe, or profound hypotension. Records from above downwards: arterial blood pressure, superior vena caval pressure, background temperature with superimposed thermovelocity pulse, and the cerebral function monitor signal. The integrated thermovelocity signal app zars as an uncalibrated, step-like trace superimposed on the lower half of the record. 
in a thesis to be presented for the degree of M.D. (Cantab.).

\section{REFERENCES}

Alexander, S. C. and Lassen, N. A. (1970). Cerebral circulatory response to acute brain disease: implications for anesthetic practice. Anesthesiology, 32, 60.

Branthwaite, M. A. (1973a). Detection of neurological damage during open-heart surgery. Thorax, 28, 464.

(1973b). Factors affecting cerebral activity during open-heart surgery. Anaesthesia, 28, 619.

Cotev, S., Lee, J., and Severinghaus, J. W. (1968). The effects of acetazolamide on cerebral blood flow and cerebral tissue $\mathrm{PO}_{2}$. Anesthesiology, 29, 471.

Halley, M. M., Reemtsma, K., and Creech, O. Jr. (1958). Cerebral blood flow, metabolism, and brain volume in extracorporeal circulation. Journal of Thoracic Surgery, 36, 506.

Harper, A. M. (1965). Physiology of cerebral blood flow. British Journal of Anaesthesia, 37, 225.

Ingvar, D. H. and Lassen, N. A. (1965). Methods for cerebral bloodflow measurements in man. British Journal of Anaesthesia, 37, 216.

Larson Jr., C. P., Ehrenfeld, W. K., Wade, J. G., and Wylie, E. J. (1967). Jugular venous oxygen saturation as an index of adequacy of cerebral oxygenation. Surgery, 62, 31.

Linden, R. J., Ledsome, J. R., and Norman, J. (1965). Simple methods for the determination of the concentrations of carbon dioxide and oxygen in blood. British Journal of Anaesthesia, 37, 77.

Lyons, C., Clark, Jr., L. C., McDowell, H., and McArthur K. (1964). Cerebral venous oxygen content during carotid thrombintimectomy. Annals of Surgery, 160, 561.
Meyer, J. S., Gotoh, F., Tomita, M., and Akiyama, M. (1966). Cerebral blood flow: new technics for recording cerebral blood flow and metabolism in $\frac{\bar{\omega}}{\bar{N}}$ subjects with cerebrovascular disease. In: Cerebral Vascular Diseases, edited by C. $\mathbf{H}$. $\stackrel{\triangle}{\varrho}$ Millikan, R. G. Siekert, and J. P. Whisnant, p. 147. Grune and Stratton, New York and Heinmann, London.

Michenfelder, J. D. and Theye, R. A. (1968). Hypothermia: effect on canine brain and whole-body $\vec{\omega}$ metabolism. Anesthesiology, 29, 1107.

and - (1969). The effects of profound hypo- $\overrightarrow{\overrightarrow{2}}$ capnia and dilution anemia on canine cerebral metabolism and blood flow. Anesthesiology, 31, 449.

Nunn, J. F. and Freeman, J. (1964). Problems of $\mathcal{C}^{\circ}$ oxygenation and oxygen transport during haemor- $\omega$ rhage. Anaesthesia, 19, 206.

Sanderson, J. M., Wright, G., and Sims, F. W. (1972). Brain damage in dogs immediately following $Z$ pulsatile and non-pulsatile blood flows in extracorporeal circulation. Thorax, 27, 275.

Shalit, M. N., Beller, A. J., Feinsod, M., Drapkin, ठ A. J., and Cotev, S. (1970). Blood flow and oxygen consumption of the dying brain. Neurology, $20,740$.

Smith, A. L. and Wollman, H. (1972). Cerebral blood flow and metabolism: effects of anesthetic drugs and techniques. Anesthesiology, 36, 378.

Wollman, H., Stephen, G. W., Clement, A. J., and Danielson, G. K. (1966). Cerebral blood flow in man during extracorporeal circulation. Journal of $\frac{\circ}{\varnothing}$ Thoracic and Cardiovascular Surgery, 52, 558.

Requests for reprints to: Dr. M. Branthwaite, Brompton Hospital, Fulham Road, London SW3 6HP. 